\title{
Preparation and characterization of carbon fiber-reinforced thermosetting composites: a review
}

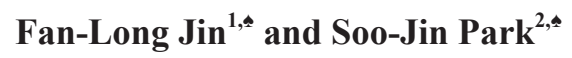 \\ ${ }^{1}$ Department of Polymer Materials, Jilin Institute of Chemical Technology, Jilin City 132022, People's Republic of China \\ ${ }^{2}$ Department of Chemistry, Inha University, Incheon 402-751, Korea
}

\section{Article Info}

Received 9 January 2015

Accepted 25 March 2015

*Corresponding Author
E-mail: jinfanlong@163.com
sjpark@inha.ac.kr

Tel: +86-432-62185319

$+82-32-8767234$

\section{Open Access}

DOI: http://dx.doi.org/

10.5714/CL.2015.16.2.067

This is an Open Access article distributed under the terms of the Creative Commons Attribution Non-Commercial License (http://creativecommons.org/licenses/ by-nc/3.0/) which permits unrestricted non-commercial use, distribution, and reproduction in any medium, provided the original work is properly cited.

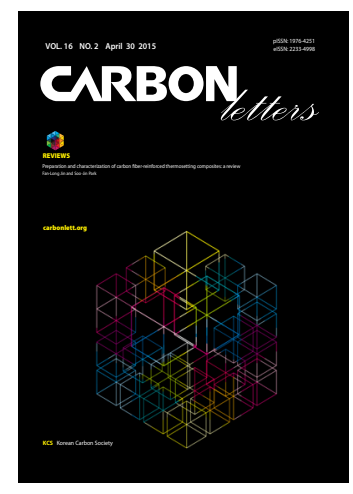

http://carbonlett.org

pISSN: $1976-4251$

elSSN: 2233-4998

Copyright $\odot$ Korean Carbon Society

\begin{abstract}
Carbon fibers (CFs) have a unique combination of properties which allow them to be widely used as reinforcing materials in advanced polymer composites. The mechanical properties of CF-reinforced polymer composites are governed mainly by the quality of interfacial adhesion between the CFs and the polymer matrix. Surface treatments of CFs are generally carried out to introduce chemical functional groups on the fiber surfaces, which provide the ability to control the surface characteristics of CFs. In this study, we review recent experimental studies concerning various surface treatment methods for CFs. In addition, direct examples of the preparation and properties of CF-reinforced thermosetting composites are discussed.
\end{abstract}

Key words: carbon fibers, thermosetting, surface treatment, composites, mechanical properties

\section{Introduction}

Carbon fibers (CFs) contain at least $92 \mathrm{wt} \%$ carbon and have a unique combination of properties, such as extremely high specific strength, stiffness, heat-resistance, light-weight, and good thermal and electrical conductivities, which enable them to be widely used in advanced composites and aircraft and automobile components [1-8].

CF-reinforced polymer (CFRP) composites are typically produced using a polymer precursor and $\mathrm{CFs}$, which are subjected to several heat treatments while applying tension. CFRP composites have a broad spectrum of engineering applications in areas including aerospace structures, sports equipment, and wind turbines because of their excellent performance characteristics, such as high specific strength, high specific stiffness, and good corrosion resistance [9-14].

The mechanical properties of CFRP composites are mainly governed by the quality of interfacial adhesion between the polymer matrix and the CFs. When load is applied to the composites, it is distributed and transferred through the fiber/matrix interfaces. However, because of their smooth nature and chemical inertness, CFs usually exhibit poor bonding behavior in polymer matrices [15-18]. For a given matrix, the interface between the fiber and the matrix will be controlled by the surface characteristics of the CFs. Consequently, surface treatments of CFs are essential to their practical application in CFRP composites. The various surface treatment methods that may be applied to CFs include wet chemical methods, dry chemical methods, electrochemical methods, plasma methods, and sizing or coating methods [19-23]. The surface treatment procedures mainly add chemical functional groups to the fiber surfaces, which increase the attraction between the fibers and the matrix, resulting in a stronger interfacial adhesion compared to pristine CFs [24-32].

The composite polymer matrices can be classified into thermosetting and thermoplastic resins. Thermosetting resins generally occur in a liquid form and are cured by applying heat or through a chemical reaction or irradiation with infrared light, ultraviolet light, or an elec- 
tron beam. Once they are cured, the thermosetting resins cannot be reheated or melted into their liquid form. Thermosetting resins are easy to process and laminate. Examples of thermosetting resins used in CFRP composites include cyanate ester resins, epoxy resins, phenolic resins, polyimide resins, and vinyl ester resins [33-43].

In this paper, the surface treatment methods for CFs and sample preparation methods for CF-reinforced thermosetting composites are reviewed in detail. In addition, the mechanical and electrical properties of CF-reinforced thermosetting composites are discussed.

\section{Surface Treatments of CFs}

\subsection{Wet chemical methods}

\subsubsection{Method I}

In this method, several bundles of $\mathrm{CF}$ s were added to a reaction flask containing a mixture of concentrated $\mathrm{H}_{2} \mathrm{SO}_{4} / \mathrm{HNO}_{3}$. The flask was placed in an ultrasonic water bath, operating at 152 $\mathrm{W}$ and $47 \mathrm{kHz}$, and maintained at $60^{\circ} \mathrm{C}$ for $2 \mathrm{~h}$. The treated substrate was then placed in a beaker and washed with distilled water until a $\mathrm{pH}$ value 7 was reached [44].

\subsubsection{Method II}

Several bundles of $\mathrm{CFs}$ were added to a reaction flask containing concentrated $\mathrm{HNO}_{3}$. The solution was refluxed at $120^{\circ} \mathrm{C}$ for $5 \mathrm{~h}$ and afterwards the $\mathrm{HNO}_{3}$-oxidized $\mathrm{CFs}$ were washed with distilled water until neutral $\mathrm{pH}$ was achieved [45].

\subsection{Dry chemical methods}

\subsubsection{Method I}

In this dry chemical method, an oxy-fluorination reaction was performed in a batch reactor made of nickel with an outer electric furnace, as shown in Fig. 1. Several bundles of CFs were

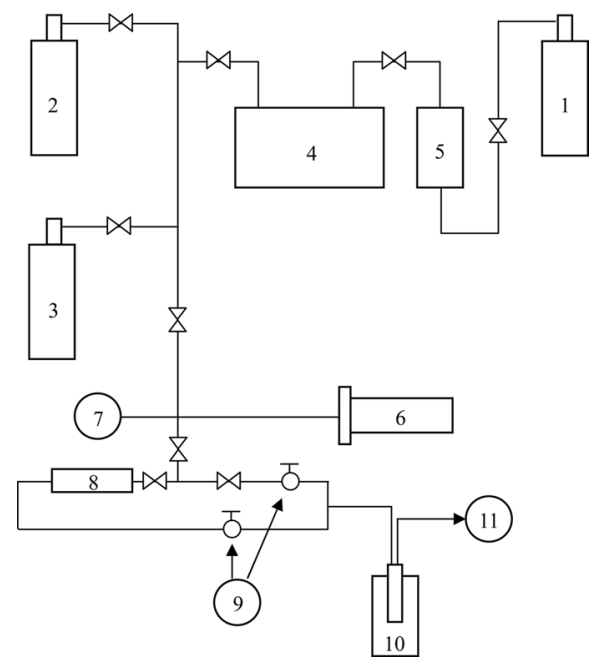

Fig. 1. Schematic diagram of fluorination reactor $[46,47] .1: F_{2}$ gas cylinder, 2: $\mathrm{N}_{2}$ gas cylinder, 3: $\mathrm{O}_{2}$ gas cylinder, 4: buffer tank, 5: HF absorber, 6: reactor, 7: pressure gauge, 8: $F_{2}$ absorber, 9: glass cock, 10 liquid nitrogen, 11: rotary vacuum pump.

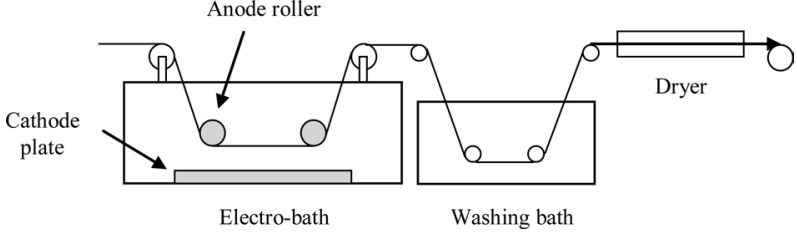

Fig. 2. Schematic representation of continuous electrolytic surface anodization process $[49,50]$.

added to the reactor. After evacuation, fluorine and oxygen mixtures were introduced into the reactor at room temperature and the reactor was subsequently heated to the treatment temperature. After the reaction was completed, the specimens were cooled to room temperature and the reactive gases were purged from the reactor with nitrogen $[46,47]$.

\subsubsection{Method II}

Several bundles of CFs were heat-treated at $300^{\circ} \mathrm{C}$ for $4 \mathrm{~h}$ in an inert atmosphere to remove the sizing agents. The CFs were then oxidized in air at $500^{\circ} \mathrm{C}$ for $1 \mathrm{~h}$ to introduce functional groups onto the surface and to increase the surface area [48].

\subsection{Electrochemical methods}

\subsubsection{Method I}

In this approach, the CFs were electrochemically treated using a laboratory pilot-scale apparatus, shown in Fig. 2. The length of the electrolytic treatment bath was $0.23 \mathrm{~m}$. A $5 \mathrm{wt} \%$ ammonium carbonate solution was used as the electrolyte and electric current densities in the range of $0-50 \mathrm{~A} / \mathrm{m}^{2}$ were used. After anodic oxidation, the anodized CFs were washed with distilled water and rinsed with acetone in a Soxhlet extractor for $2 \mathrm{~h}$ to remove any surface impurities or residual oxides $[49,50]$.

\subsubsection{Method II}

The surfaces of the CFs were treated using a laboratory pilot-scale apparatus. $\mathrm{H}_{3} \mathrm{PO}_{4}$ solution $(10 \mathrm{wt} \%)$ was used as the electrolyte and a constant oxidation rate was used. Electric current densities in the range of $0-1.6 \mathrm{~A} / \mathrm{m}^{2}$ were applied. After anodic oxidation, the anodized CFs were washed with distilled water and rinsed with acetone in a Soxhlet extractor for $2 \mathrm{~h} \mathrm{[51-53].}$

\subsection{Plasma methods}

\subsubsection{Method I}

In this plasma based method, the reactor was prepared by evacuation, and then a constant pressure of $10 \mathrm{~Pa}$ was maintained using argon and oxygen gases. The fibers were mounted on a homemade fixture that could be rotated freely between the electrodes and handled outside the reactor. The fibers were treated at plasma power in the range of $15-150 \mathrm{~W}$ in various plasma environments for 10-30 min. At the end of each treatment, the treated fibers were subjected to $30 \mathrm{~min}$ of post-treatment under identical conditions [54].

\subsubsection{Method II}

Atmospheric pressure plasma treatments were performed us- 
ing dielectric barrier discharges (DBD) operating in air. Two circular copper electrodes were placed in the DBD plasma configuration. Each electrode was covered with a quartz glass plate with a thickness of $2 \mathrm{~mm}$ and a circular area that was $210 \mathrm{~mm}$ in diameter. The gap between the two quartz glass plates was $6 \mathrm{~mm}$. A pulsed AC power supply with a voltage of $8 \mathrm{kV}$ and frequency of $8 \mathrm{kHz}$ was used. The discharge current and peak pulse current were $40 \mathrm{~mA}$ and $300 \mathrm{~mA}$, respectively. The samples were placed on the lower quartz glass plate. Upon discharge, a large number of dense filamentary microdischarges were generated from the upper electrode and the surfaces of the samples were bombarded with the microdischarges [55].

\subsection{Sizing or coating methods}

\subsubsection{Method I}

In this coating method, an aqueous solution containing $1 \mathrm{wt} \%$ of a silane (used as a coupling agent) was prepared using 50 vol $\%$ of methanol, and the $\mathrm{pH}$ was adjusted to 4 using acetic acid. The solution was stirred for $2 \mathrm{~h}$. Several bundles of CFs were immersed in the solution for a few minutes and the treated $\mathrm{CFs}$ were dried in air at $120^{\circ} \mathrm{C}$ for $30 \mathrm{~min}[56,57]$.

\subsubsection{Method II}

Several bundles of CFs were activated in $\mathrm{HNO}_{3}$ for $30 \mathrm{~min}$. Following activation in $\mathrm{HNO}_{3}$, the CFs were sequentially activated in tin chloride and palladium chloride activation solutions. Following this, the CFs were plated with nickel by dipping in a nickel bath. Prior to use, residual chemicals used were removed using Soxhlet extraction by boiling with acetone at $70^{\circ} \mathrm{C}$ for $2 \mathrm{~h}$. Finally, the CFs were washed several times with distilled water and dried in a vacuum oven at $120^{\circ} \mathrm{C}$ for $12 \mathrm{~h}[58,59]$.

\section{Sample Preparation Methods}

\subsection{Cyanate ester-based composites}

\subsubsection{Preparation method I}

In this preparation approach, single tow samples were impregnated in a bath containing solvated cyanate ester monomers and then passed through a die to remove the excess resin. The impregnated tow was cut, mounted on a frame, cured sequentially at $170^{\circ} \mathrm{C}$ for $1 \mathrm{~h}$ and $180^{\circ} \mathrm{C}$ for $2 \mathrm{~h}$, and post-cured at $220^{\circ} \mathrm{C}$ for $1 \mathrm{~h}$ in an air oven [60]

\subsubsection{Preparation method II}

Impregnated CFs were prepared using a dip-winding technique. A composite layout involving the preparation of 10-ply unidirectional laminates was used for the majority of the mechanical tests. All the laminate samples were cured sequentially at $180^{\circ} \mathrm{C}$ for $3 \mathrm{~h}$ and post-cured at $220^{\circ} \mathrm{C}$ for $1 \mathrm{~h}$ in an autoclave [61].

\subsubsection{Preparation method III}

After pre-polymerization, cyanate esters were cooled and added to acetone. The pre-impregnated CFs were then prepared using a dip-winding technique. When the amount of volatile components reached $5 \mathrm{wt} \%$ after drying at room temperature, the prepreg was dried. After that, the prepreg cloth was tailored, stacked, and pressure-molded by following certain regulations. All the laminate samples were cured sequentially at $120^{\circ} \mathrm{C}$ for 1 $\mathrm{h}, 150^{\circ} \mathrm{C}$ for $1 \mathrm{~h}$, and $180^{\circ} \mathrm{C}$ for $2 \mathrm{~h}$, and post-cured at $220^{\circ} \mathrm{C}$ for $1 \mathrm{~h}$ in an autoclave [62].

\subsection{Epoxy-based composites}

\subsubsection{Preparation method I}

In this composite preparation method, the desired amounts of epoxy resins and short $\mathrm{CFs}$ were mixed at $80^{\circ} \mathrm{C}$ for $1 \mathrm{~h}$, and then hardener was added. The resulting mixture was stirred for 30 min followed by sonication for 10 min using an ultrasonicator. The bubble-free ultrasonicated mixture was poured into a preheated mold that was sprayed with a mold-release agent. Curing was performed sequentially at $110^{\circ} \mathrm{C}$ for $1 \mathrm{~h}, 140^{\circ} \mathrm{C}$ for $2 \mathrm{~h}$, and $170^{\circ} \mathrm{C}$ for $1 \mathrm{~h}$ in a convection oven [63].

\subsubsection{Preparation method II}

Unidirectional composite laminates were prepared by continuous impregnation of $\mathrm{CFs}$ using a drum-winding technique for manufacturing prepregs with subsequent hot-pressing. The composites were prepared by filament winding, where the CF roving was continuously soaked in the epoxy matrix bath, before winding on the mandrel. Specimens were prepared from laminates composed of 22 plies and fabricated in a hot-press at $150^{\circ} \mathrm{C}$ and $7.4 \mathrm{MPa}$ for $150 \mathrm{~min}$, by a vacuum bagging method used in conventional composite processing $[64,65]$.

\subsubsection{Preparation method III}

Here, the CFs were placed in the middle of a standard dogbone silicon mold. Both ends of the CFs were stuck to the mold frame to hold them straight along the mold. The epoxy resin was heated and then stirred at a low speed with a hardener. Subsequently, the CFs were brushed with the epoxy/hardener mixture to completely wet them with the polymeric phase and eliminate any possible trapped bubbles. Subsequently, the mixture was poured into the mold and cured at $70^{\circ} \mathrm{C}$ for $72 \mathrm{~h}$ [66].

\subsubsection{Preparation method IV}

Composite laminates were produced using the resin transfer molding process. The CFs were placed in the middle of the mold. Epoxy resin was heated and the hardener was added. The resin was then degassed in a vacuum chamber and subsequently injected into the mold with changing pressure. The samples were cured at $70^{\circ} \mathrm{C}$ for $4 \mathrm{~h}$ and post-cured at $150^{\circ} \mathrm{C}$ for $1 \mathrm{~h}[67]$.

\subsection{Phenolic resin-based composites}

\subsubsection{Preparation method I}

In this composite preparation, CFs and phenolic resin in methanol were mixed and stirred in a beaker at $30^{\circ} \mathrm{C}$. Composite plates with a thickness of $2 \mathrm{~mm}$ were then prepared and dried in a convection oven at $40^{\circ} \mathrm{C}$ to remove methanol. The $\mathrm{CF} /$ phenolic resin composites were prepared by stacking 4 plies of plates and isothermally pressing with a hot-press at $150^{\circ} \mathrm{C}$ for $30 \mathrm{~min}$ [68]. 


\subsubsection{Preparation method II}

In this case, the composites were prepared by filament-winding, where the CFs were continuously soaked in a phenolic matrix bath before being wound onto the mandrel. Specimens were prepared from laminates composed of 22 plies and fabricated in a hot-press at $150^{\circ} \mathrm{C}$ and $7.4 \mathrm{MPa}$ for 150 min using a vacuum bagging method [59].

\subsection{Polyester-based composites}

For this approach, polyester resin, accelerator, initiator, and short CFs were mixed and stirred in a beaker. $\mathrm{CF} /$ polyester composite samples were prepared by cast-molding between two parallel copper electrodes. The polyester resin was then cured at room temperature for $24 \mathrm{~h}[69,70]$.

\subsection{Polyimide-based composites}

\subsubsection{Preparation method I}

In this method, powdered polyimide prepolymers were uniformly deposited on CFs using electrostatic powder deposition. Subsequently, dry flexible prepreg was obtained after impregnating the CFs with the prepolymer at $220^{\circ} \mathrm{C}$ for $1 \mathrm{~min}$ in a heated calendar, which was used to uniformly wet the fibers with the prepolymer melt. The composites were prepared by molding at $0.3 \mathrm{MPa}$ and $330^{\circ} \mathrm{C}$ for $1 \mathrm{~h}$, with subsequent post-curing at $350^{\circ} \mathrm{C}$ for $5 \mathrm{~h}[71]$.

\subsubsection{Preparation method II}

Prepregging of polyimide was carried out by solvent impregnation of the CFs using a solution of the monomers in methanol. These semi-prepregs were heated up to $220^{\circ} \mathrm{C}$ to reduce the methanol and to form a norbornene-endcapped oligoimide. $\mathrm{CF} /$ polyimide composites were prepared by molding at $0.3 \mathrm{MPa}$ and $315^{\circ} \mathrm{C}$ for $1 \mathrm{~h}$, with subsequent post-curing at $330^{\circ} \mathrm{C}$ for $3 \mathrm{~h} \mathrm{[72]}$.

\subsubsection{Preparation method III}

Here, a poly(amic acid) solution was first diluted with ethanol. CFs were wound on a frame and impregnated with the solution at room temperature using a layer-by-layer impregnation technique. The pre-impregnated fibers were subsequently dried in a vacuum oven and the dried prepregs were then placed in a preheated leaky mold at $204^{\circ} \mathrm{C}$ for 3 min under contact pressure before the application of full pressure $(1.75 \mathrm{MPa})$ for 30 $\mathrm{min}$. The press was cooled to $30^{\circ} \mathrm{C}$ before releasing the pressure. The laminates were subsequently post-cured at $290^{\circ} \mathrm{C}$ and $0.175 \mathrm{MPa}$ for $4 \mathrm{~h}$ and then at $320^{\circ} \mathrm{C}$ for $3 \mathrm{~h}$ in an air-oven under atmospheric pressure [73].

\subsubsection{Preparation method IV}

The CF-reinforced polyimide substrates were cleaned with acetone to remove grease or moisture, and then grit-blasted with 46-mesh corundum powders. The pressure of the compressed air used for grit-blasting was $0.4 \mathrm{MPa}$. To study the influence of preheating specimens were heated in an electric oven to a temperature in the range of $100^{\circ} \mathrm{C}-300^{\circ} \mathrm{C}$, and held for $10 \mathrm{~min}$. The samples were coated immediately after removing them from the oven [73].

\subsection{Vinyl ester-based composites}

\subsubsection{Preparation method I}

In this ester-based preparation method, 2-butanone peroxide $(0.8 \mathrm{wt} \%)$ and cobalt naphthenate (accelerator, $0.2 \mathrm{wt} \%)$ were added to vinyl ester resin. Then, a vapor-grown $\mathrm{CF} / \mathrm{resin}$ premixture $(33.3 \mathrm{wt} \%)$ containing the catalyst was prepared by high-speed mechanical stirring. The remaining catalyst-loaded resin was hand-mixed with the pre-mixture. After placing the $\mathrm{CF} /$ vinyl ester mixture for $1 \mathrm{~h}$ at room temperature, it was poured into an aluminum mold and the mold was placed on a hot-press. The mold was then removed from the press, placed in an oven at $65.5^{\circ} \mathrm{C}$ for $1.5 \mathrm{~h}$, and cooled to room temperature [74].

\subsubsection{Preparation method II}

The vinyl ester resin was cured by incorporating $2 \%$ methyl ethyl ketone peroxide (MEKP, catalyst), 0.3\% cobalt naphthenate, and $0.05 \%$ 2,4-pentanedione. The above chemicals were mixed with vinyl ester resin and the mixture was poured into a mold. The entrapped air bubbles were removed carefully with a roller and the mold was closed for curing at a temperature of $30^{\circ} \mathrm{C}$ for $24 \mathrm{~h}$ at a constant pressure of $10 \mathrm{~kg} / \mathrm{cm}^{2}$ [75].

\subsubsection{Preparation method III}

CFs and vinyl ester resin were mixed uniformly using a mechanical stirrer. Approximately $0.3 \%$ of cobalt naphthenate was mixed thoroughly in the vinyl ester resin followed by the addition of $2 \%$ MEKP, prior to fiber reinforcement. 2,4-pentanedione $(0.05 \mathrm{wt} \%)$, which is used as a retarder for extending the gel reaction time, was also added. The composite sheets were prepared by the conventional hand-lay-up technique. The entrapped air bubbles were removed carefully with a roller before closing the mould. The castings were subjected to a constant pressure of $10 \mathrm{~kg} / \mathrm{cm}^{2}$ for $24 \mathrm{~h}$, to allow proper curing at room temperature [76].

\section{Mechanical and Electrical Properties}

\subsection{Cyanate ester-based composites}

Barton et al. [60] prepared CF pre-impregnated tapes from a range of prepolymers containing blends of propenylfunctionalized cyanate ester oligomers and commercial bismaleimide (BMI) monomers. Cured neat resin plaques and $\mathrm{CF}$ composites were prepared by autoclave-molding. All the BMI/ cyanate ester blends showed an increase in flexural strength and flexural modulus over the reference homopolymers. When incorporated into a blend, both BMI and cyanate ester showed significant improvements in fracture toughness over their respective homopolymers, owing to the morphological changes within the interpenetrating polymer network resin matrices, which reduced the crosslinking density in the homopolymer matrices.

Ren et al. [61] manufactured epoxy resin-modified bisphenol-A dicyanate (BADCy) and associated CF-reinforced composites. Analyses of their mechanical properties revealed that the flexural strength and impact strength of BADCy could be improved from $95.6 \mathrm{MPa}$ and $9.24 \mathrm{~kJ} / \mathrm{m}^{2}$ to $117.8 \mathrm{MPa}$ and 12.6 
$\mathrm{kJ} / \mathrm{m}^{2}$, respectively, by introducing $5 \mathrm{wt} \%$ epoxy resin. Scanning electron microscopy (SEM) images indicated good adhesion between the CFs and BADCy in the composites. Ren et al. [62] also studied the effect of epoxy sizing on the mechanical and morphological properties of $\mathrm{CF} /$ cyanate ester composites. Their results indicated that the CFs sized by epoxy resin were able to improve the flexural strength and interlaminar shear strength (ILSS) of the composites. Analyses of the micro-morphology of the fracture surfaces showed reduced flaws in the fiber-matrix interfaces when sized fiber was used.

Chung and Seferis [77] evaluated the thermal degradation of $\mathrm{CF} /$ cyanate ester composites. Their results revealed that the interface between the resin and the CFs in the composites was uniform without any visible voids in the matrix. As the composites aged, their glass transition temperature $\left(T_{g}\right)$ decreased dramatically, implying a decrease in the relaxation time.

\subsection{Epoxy-based composites}

Dong et al. [63] studied the improvement in the fracture toughness of diglycidylether of bisphenol-A (DGEBA) epoxy resins reinforced with short CFs. Their results showed that the fracture toughness of the $\mathrm{CF} /$ epoxy composites was significantly improved compared to neat epoxy resin, as shown in Fig. 3. SEM micrographs indicated that a relatively rough surface with shear deformation and tortuous cracks was formed, which prevented deformation and crack propagation and provided higher fracture toughness in the DGEBA/CF composites.

Park et al. [64] proposed a new method based on a nanoscale Ni-P alloy coating on CF surfaces to improve the interfacial properties between the fibers and epoxy matrix in the composites. Their results revealed that the $\mathrm{O}_{1 \mathrm{~s}} / \mathrm{C}_{1 \mathrm{~s}}$ ratio or nickel and phosphorous amounts increased as the electroless nickel plating process progressed. In addition, ILSS also improved slightly. Further, impact properties were significantly improved in the presence of the Ni-P alloy coating on CF surfaces, thereby increasing the ductility of CF/epoxy composites, as shown in Fig 4. Park et al. [65] also investigated the effect of oxy-fluorination on the physicochemical properties of CF-reinforced epoxy composites. Their results showed that the oxy-fluorination

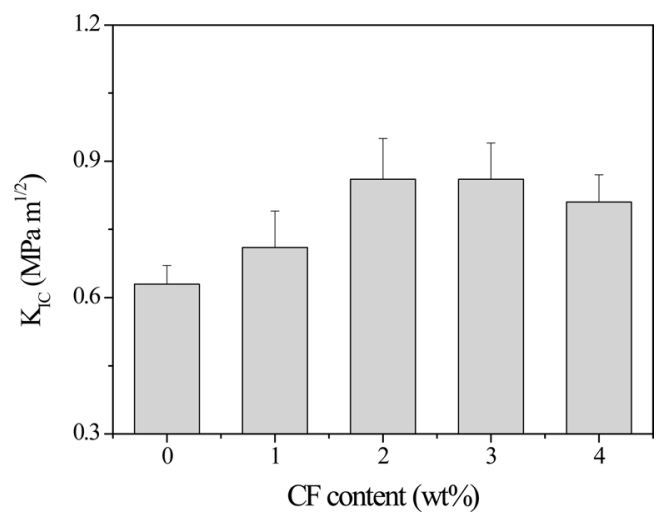

Fig. 3. Toughness properties expressed in terms of critical stress intensity factor $\left(\mathrm{K}_{\mathrm{C}}\right)$ as a function of carbon fiber (CF) content for DGEBA/ CF composites [48]. DGEBA: diglycidylether of bisphenol-A.

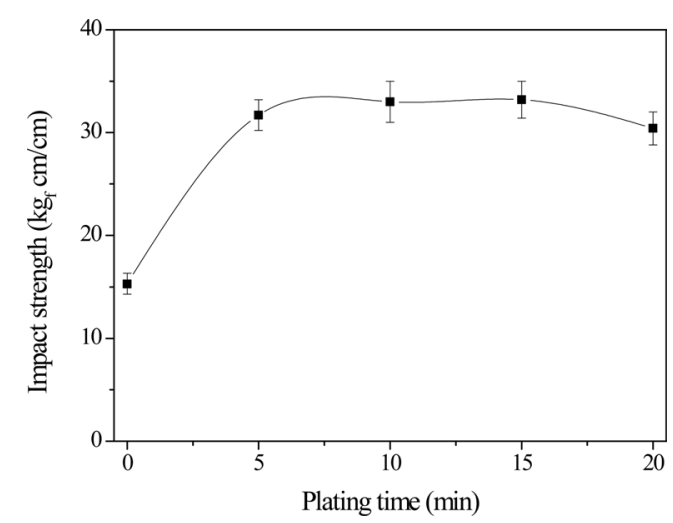

Fig. 4. Evolution of impact strength as a function of electroless nickel plating time [49].

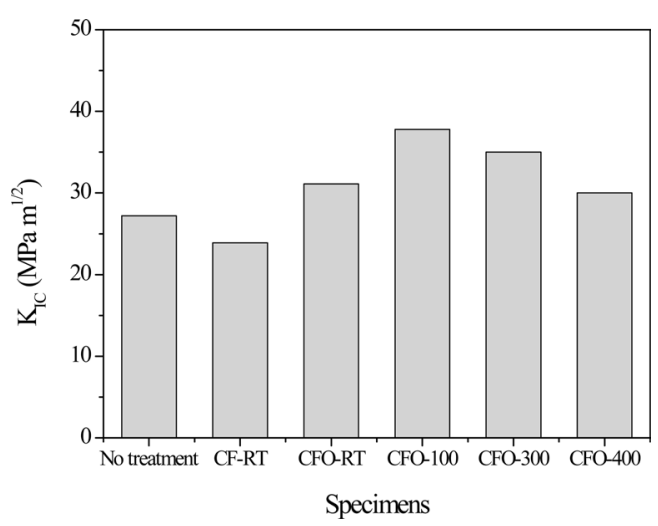

Fig. 5. Fracture toughness $\left(\mathrm{K}_{\mathrm{I}}\right)$ of oxy-fluorinated carbon fiber (CF)reinforced composites [50]. No treatment: $7.02(\mathrm{pH})$ and $15 \mathrm{meq} / \mathrm{g}$ (acid value), CF-RT: 6.98 and $18.2 \mathrm{meq} / \mathrm{g}$, CFO-RT: 6.95 and $18.5 \mathrm{meq} / \mathrm{g}$, CFO100: 6.94 and $22.1 \mathrm{meq} / \mathrm{g}$, CFO-300: 6.94 and $20.3 \mathrm{meq} / \mathrm{g}$, CFO-400: 6.95 and $18.4 \mathrm{meq} / \mathrm{g}$.

reaction introduced fluorine and oxygen functional groups on the CF surfaces which were more efficient and reactive from the point of view of interfacial reactions with matrix materials. The formation of $\mathrm{C}-\mathrm{F}_{\mathrm{x}}$ physical bonds between the $\mathrm{CFs}$ and fluorine increased the surface polarity of the fibers, resulting in an increase in the mechanical interfacial properties of the $\mathrm{CF} /$ epoxy composites (Fig. 5), owing to an improvement in the interfacial adhesion between the fibers and matrix resins. Park and Kim [52] also studied the role played by acidic functional groups on CF surfaces in enhancing the interfacial adhesion of $\mathrm{CF} /$ epoxy composites. Their results indicated that oxygen functional groups such as $-\mathrm{OH}, \mathrm{O}-\mathrm{C}=\mathrm{O}, \mathrm{C}=\mathrm{O}$, and $\mathrm{C}-\mathrm{O}$, were attached to the $\mathrm{CF}$ surfaces after ozone treatment. The mechanical interfacial properties of ozone-treated CF/epoxy composites were improved compared to those of untreated $\mathrm{CF} /$ epoxy composites.

Moaseri et al. [66] introduced a microwave-assisted approach for the functionalization of CFs via aliphatic and aromatic diamines, in order to enhance the interactions between the CFs and epoxy matrix. Their results revealed that the proposed functionalization procedure was able to functionalize the CFs effectively without any discernible structural disruption. The 


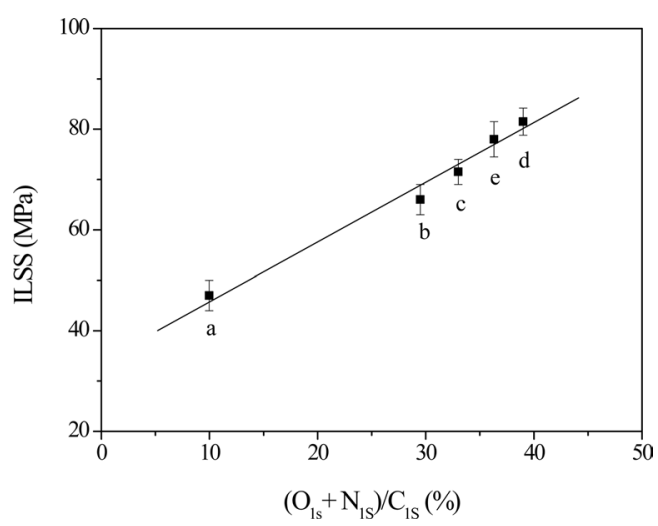

Fig. 6. Interlaminar shear strength (ILSS) of carbon fiber (CF)/epoxy composites as a function of $\left(\mathrm{O}_{1 \mathrm{~s}}+\mathrm{N}_{1 \mathrm{~s}}\right) / \mathrm{C}_{1 \mathrm{~s}}$ atomic ratio of $\mathrm{CFs}$ [34]. a: 0 , b: $10 \mathrm{~A} / \mathrm{m}^{2}, \mathrm{c}: 20 \mathrm{~A} / \mathrm{m}^{2}, \mathrm{~d}: 30 \mathrm{~A} / \mathrm{m}^{2}$, e: $50 \mathrm{~A} / \mathrm{m}^{2}$ (current density).

functionalized CFs demonstrated better compatibility with the epoxy resin, leading to considerable improvements in the mechanical properties of the CF/epoxy composites.

Ryu et al. [49] analyzed the interfacial properties of $\mathrm{CF} /$ epoxy composites. Their results showed that the $\mathrm{O}_{1 \mathrm{~s}} / \mathrm{C}_{1 \mathrm{~s}}$ and $\mathrm{N}_{1 \mathrm{~s}} / \mathrm{C}_{1 \mathrm{~s}}$ ratios of the fiber surfaces increased with an increase in the current intensity during electrochemical treatment. The treatment is possibly suitable for incorporating CFs in a polar organic matrix, which would result in an increase in the ILSS of the composites, as shown in Fig. 6.

Siegfried et al. [67] investigated the effect of carbon nanotubes (CNTs) on the impact and residual properties of woven $\mathrm{CF} /$ epoxy composites. Their results indicated that the CNTs exert dual effects on the composite properties. While they improved the mode II interlaminar fracture toughness and damage tolerance of the composites, they also make the composites more susceptible to the onset of matrix cracks, leading to a larger delamination area after impact.

\subsection{Phenolic resin-based composites}

Choi et al. [68] studied the effect of a coupling agent on the electrical and mechanical properties of short $\mathrm{CF} /$ phenolic resin composites. The electrical conductivity of the composite was about $10^{-3}-10^{-1} \mathrm{~S} / \mathrm{cm}$. Glutaric dialdehyde, which was used as a coupling agent, was able to improve the mechanical properties of the composite by improving the flow and dispersion of CFs in the matrix and by enhancing the chemical bond between the CFs and phenolic resin during compression molding.

Park and Jang [59] investigated the interfacial characteristics and fracture toughness of $\mathrm{CF} /$ phenolic resin composites electrolytically plated with nickel. Their results revealed that the presence of oxygen functional groups and metallic nickel on the fiber surfaces significantly affected the mechanical interfacial behavior of the composites, resulting in increased surface polarity, as shown in Fig. 7. A good correlation between the concentration of the surface oxygen functional groups and the mechanical interfacial properties, and between wettability and $\mathrm{K}_{\mathrm{IC}}$, was established, and a current density of $10 \mathrm{~A} / \mathrm{m}^{2}$ was found to be the optimum condition for this system.

Li et al. [78] studied the effect of electropolymer sizing

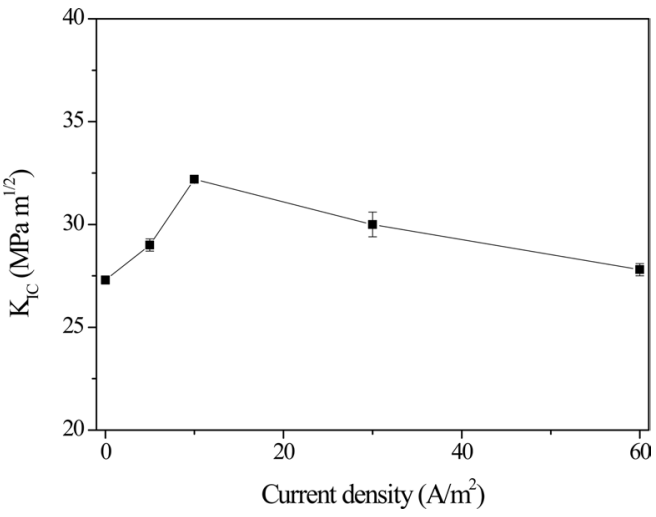

Fig. 7. Evolution of $K_{\mathrm{c}}$ of carbon fiber/phenolic resin composites with current density [44].

of $\mathrm{CFs}$ on the mechanical properties of $\mathrm{CF} /$ phenolic resin composites. Their results showed that the electropolymer-sized CFs tended to reduce the surface energy, owing to a decrease in dispersion, along with an increase in the polymer film on the CF surface, which plays an important role in improving the mechanical properties of the composites. Compared to the composites reinforced by unsized CFs, the impact strength, flexural strength, and ILSS of the composites reinforced with CFs sized by m-phenylenediamine were improved by $44 \%$, $68 \%$, and $87 \%$, respectively. Similarly, composites reinforced with CFs sized by phenol showed improvements of $66 \%, 100 \%$, and $112 \%$, whereas those reinforced by CFs sized with acrylic acid showed improvements of $20 \%, 80 \%$, and $100 \%$ for impact strength, flexural strength, and ILSS, respectively.

Marković and Marinković [79] investigated the pyrolysis of $\mathrm{CF} /$ phenol-formaldehyde resin composites. Two temperature regions could be distinguished in the pyrolysis of the composites, namely below $770 \mathrm{~K}$, where the CFs held the composite structure, resisting the tendency of the resin to produce composite shrinkage; and above $770 \mathrm{~K}$, where the volume and porosity of the composites abruptly increased, owing to a weakening of the fiber/resin adhesion.

Singh et al. [80] prepared phenolic resin composite sheets filled with a mixture of reduced graphene oxide (RGO), $\gamma-\mathrm{Fe}_{2} \mathrm{O}_{3}$, and CFs. Their results revealed the presence of nanoparticles of $\gamma-\mathrm{Fe}_{2} \mathrm{O}_{3}$ and $\mathrm{CF}$, which gave flexural strength to the composite sheets. Their results also indicated that the nanoparticles of $\gamma-\mathrm{Fe}_{2} \mathrm{O}_{3}$ embedded between the RGO layers enhanced the interfacial polarization and the effective anisotropic energy of the sheets, which contributed to an increase in scattering and led to high shielding effectiveness compared to conventional materials.

\subsection{Polyester-based composites}

Vilčáková et al. [69] studied the electrical behavior of polyester resins filled with different amounts of short CFs. Percolation of the composites filled with $\mathrm{CFs}$ set in at low particle concentrations of $1-2 \mathrm{wt} \%$. For certain filler concentrations above the percolation threshold, the semiconducting characteristics of the composites persisted only at lower temperatures and the composites started exhibiting non-conducting behavior, 
owing to the switching effect. Only at a somewhat higher CF content of $7 \mathrm{wt} \%$, the composites exhibited clear conducting behavior, irrespective of the structural change of the matrix at the $\mathrm{T}_{\mathrm{g}}$. Vilčáková et al. [70] also investigated the electrical conductivity of polyester resin composites filled with short CFs and confirmed a very low percolation threshold (0.7-0.8 vol\% $\mathrm{CFs}$ ). In contrast to the S-shaped curves calculated according to the percolation theory of composites of globular particles, the dependence between conductivity and fiber content determined experimentally was almost linear, after a steep increase in the percolation region. This atypical behavior was explained by a different mechanism for the formation of fibrous versus globular conducting structures above the percolation threshold. An increase in the scatter of conductivity values observed at the percolation threshold as a consequence of the great fluctuation in the fiber arrangement manifested itself in the conductivitytemperature correlations.

Using optical retardation measurements, Wyatt and Ashbee [81] showed that debonding occurs in polyester thin films containing dispersions of completely embedded CFs. Resin swelling during immersion at $20^{\circ} \mathrm{C}$ is insufficient to produce tensile interfacial stress. Untreated glass fibers are still rapidly debonded, whereas CFs retain their interfacial bond. This difference in behavior at low temperatures is attributed to the difference in the chemical nature of the two types of surfaces, i.e., untreated glass fibers are hydrophilic, whereas $\mathrm{CFs}$ are hydrophobic.

Sadeghian et al. [82] prepared carbon nanofiber (CNF)reinforced glass fiber/polyester composites using vacuum assisted resin transfer molding (VARTM). They consistently observed a significant improvement in the critical energy release rates of mode I delamination $\left(\mathrm{G}_{\mathrm{IC}}\right)$, as $1 \mathrm{wt} \%$ of $\mathrm{CNF}$ was added to toughen the polyester resin. Microscopic pictures showed that the fracture surfaces of the $1 \mathrm{wt} \%$ CNF-reinforced polyester/ glass fiber composites were more complex than those of regular polyester/glass fiber composites.

Hsiao and Gangireddy [83] investigated the springin phenomenon of CNF-glass fiber/polyester composites synthesized using VARTM. Their results showed that the springin angles of the L-shaped composites were effectively restrained by the CNFs. An analytical model and a 3D finite element analysis (FEA) model were developed to predict the spring-in phenomenon and to understand the role of CNFs in reducing the spring-in angle.

Srivastava et al. [84] implanted tricalcium phosphatepolyvinyl alcohol-filled CF-reinforced polyester composites into the bone marrow of rabbits. These composites showed a combination of advantageous properties including improved tensile strength, compressive strength, bending strength, and biocompatibility compared to CF-reinforced polyester composites. In addition, CFs showed high modulus and strength for implanted materials without causing any adverse effects. Thus, these materials may prove to be useful for novel applications in the biomedical field.

\subsection{Polyimide-based composites}

Yudin et al. [71] studied the carbonization behavior of polyimide resins reinforced with CFs. Their results showed that the polyimide resins based on acetyl derivatives of aromatic diamines exhibit low weight loss during carbonization, which makes them promising candidates for use in carbon-carbon composites. The low weight loss exhibited by CF-reinforced polyimide composites was due to strong fiber-matrix interactions, which could result from the cross-linking between the fiber surface and the matrix.

Mascia et al. [72] investigated the structure-property relationships of CF composites based on polyimide/silica ceramers. CF composites produced from ceramer solutions ( $\mathrm{CF} /$ ceramers) were found to exhibit lower thermal expansion and a greater retention of flexural and interlaminar shear properties at elevated temperatures compared to polyimide-matrix composites $(\mathrm{CF} /$ polyimide). $\mathrm{CF} /$ ceramer composites were also found to exhibit better thermal oxidative stability at $350^{\circ} \mathrm{C}$ compared to the corresponding $\mathrm{CF} /$ polyimide composites, although the ceramers with higher silica content developed a substantial amount of porosity.

Liu et al. [73] studied the effect of bond coat on the shear adhesion strength of erosion and thermal resistant coatings on CFreinforced polyimides. Their results indicated that the substrate was thermally damaged when $\mathrm{Ni}_{3} \mathrm{Al}$ or copper was deposited as a bond coat, and the bond coat was delaminated from the substrate. Arc-sprayed and plasma-sprayed aluminum and zinc could be used as bond coat materials. In the case of zinc as a bond coat material, the deposition method had little influence on the shear adhesion strength.

Xie et al. [85] improved the adhesion between CFs and polyimides with atmospheric pressure plasma treatment. Their results showed that the oxygen concentration significantly increased after plasma treatment and the oxygen-containing functional groups reached their maximum levels after a treatment time of $32 \mathrm{~s}$. The interfacial shear strength was improved by $21 \%$ after plasma treatment for $32 \mathrm{~s}$.

Naganuma et al. [86] investigated the effect of a compliant polyimide nanocoating on the tensile strength of polyacrylonitrile-based CFs. Their results clearly demonstrated that the compliant polyimide nanocoating was effective in improving the tensile strength and Weibull modulus of CFs.

\subsection{Vinyl ester-based composites}

$\mathrm{Xu}$ et al. [74] studied the electrical and mechanical properties of vapor-grown $\mathrm{CF} /$ vinyl ester composites. Their results showed that the percolation behavior occurred along with a sharp drop in resistivity at a CF content of $2-3 \mathrm{wt} \%$. Composites made from $\mathrm{HNO}_{3}$-oxidized $\mathrm{CFs}$ were insulators even at a $\mathrm{CF}$ content of $15 \mathrm{wt} \%$. Incorporating CFs had little influence on the flexural moduli. In addition, it caused a decrease in the flexural strength and increase in the storage moduli.

Kumar et al. [75] investigated the thermo-mechanical properties and erosion performance of short CF-reinforced vinyl ester composites. Composites with $30 \mathrm{wt} \% \mathrm{CFs}$ exhibited superior thermo-mechanical response along with high energy dissipation/damping ability, in addition to a constant storage modulus without any substantial decay until $60^{\circ} \mathrm{C}$. A correlation was observed between the inverse of loss-modulus and erosion rate, which conceptually establishes a possible mechanistic equivalence between erosion and dynamic mechanical loading modes. Kumar et al. [76] also studied the erosion of fiber- 
reinforced hybrid composites consisting of vinyl ester resin and different weight fractions of short E-glass/CF. The storage moduli of the composites steadily increased up to $3927 \mathrm{MPa}$, corresponding to $40 \mathrm{wt} \%$ of fibers, which may be due to the maximum stress-transfer between the fibers and matrix. The Cole-Cole plots of the hybrid composites showed an imperfect semicircle, indicating the heterogeneity of the system and good interfacial adhesion between different hybrid configurations.

Verghese et al. [87] investigated the mechanical and viscoelastic properties of unidirectional $\mathrm{CF} / \mathrm{vinyl}$ ester composites. The temperature sensitivity of the horizontal logarithmic shift factors (cooperativity) was found to vary with the sizing used to pretreat the CFs. The observed variations in the experimental trends of cooperativity as a function of fiber sizing for the composites were found to deviate significantly from theoretical predictions.

Wonderly et al. [88] compared the mechanical properties of glass fiber and CF-reinforced vinyl ester composites. The CF laminates proved to be mechanically superior under loading conditions, where the strength is mainly fiber-dominated (i.e., under tensile loading and indentation). The ratio of the CF laminate strength to the glass fiber laminate strength for laminates of equal thickness was similar to the ratio of the CF tensile strength to the glass fiber tensile strength. In the case of CF specimens, the failure was more localized and the strength values exhibited more scatter compared to the glass fiber specimens.

\section{Summary}

In this paper, we have reviewed the various surface treatment methods for CFs. Those surface treatment procedures mainly introduce chemical functional groups onto the fiber surfaces, thereby increasing the attraction between the fiber and polymer matrix. Sample preparation methods for CF-reinforced thermosetting composites are important for achieving uniform dispersion of CFs in the matrix and for increasing the interfacial adhesion between the CFs and the matrix. Furthermore, we have discussed the preparation methods for various types of composites in detail and have also reviewed the mechanical and electrical properties of the composites. Recent studies have focused on the preparation and characterization of $\mathrm{CF} / \mathrm{CNT} /$ thermosetting ternary composites, in order to significantly improve the comprehensive performance of the resulting composites.

\section{Acknowledgements}

This work was supported by the Carbon Valley Project by Ministry of Trade, Industry and Energy (A0077 00060).

\section{References}

[1] Diaz A, Guizar-Sicairos M, Poeppel A, Menzel A, Bunk O. Characterization of carbon fibers using X-ray phase nanotomography. Carbon, 67, 98 (2014). http://dx.doi.org/10.1016/j.carbon. 2013.09.066.
[2] Seo MK, Min BG, Park SJ. Carbon fibers (II): recent technical trends and market prospects of carbon fibers. Carbon Lett, 9, 324 (2008).

[3] Shin HK, Park M, Kang PH, Choi HS, Park SJ. Preparation and characterization of polyacrylonitrile-based carbon fibers produced by electron beam irradiation pretreatment. J Ind Eng Chem, 20, 3789 (2014). http://dx.doi.org/10.1016/j.jiec.2013.12.080.

[4] Zhou G, Byun JH, Lee SB, Yi JW, Lee W, Lee SK, Kim BS, Park JK, Lee SG, He L. Nano structural analysis on stiffening phenomena of PAN-based carbon fibers during tensile deformation. Carbon, 76, 232 (2014). http://dx.doi.org/10.1016/j.carbon.2014.04.073.

[5] Seo MK, Park SH, Kang SJ, Park SJ. Carbon fibers (III): recent technical and patent trends. Carbon Lett, 10, 43 (2009).

[6] Speiser M, Henzler S, Hageroth U, Renfftlen A, Müller A, Schawaller D, Sandig B, Buchmeiser MR. Hollow carbon fibers with tailored porosity and rim-thickness. Carbon, 63, 554 (2013). http:// dx.doi.org/10.1016/j.carbon.2013.07.036.

[7] Alway-Cooper RM, Anderson DP, Ogale AA. Carbon black modification of mesophase pitch-based carbon fibers. Carbon, 59, 40 (2013). http://dx.doi.org/10.1016/j.carbon.2013.02.048.

[8] Yang KS, Kim BH, Yoon SH. Pitch based carbon fibers for automotive body and electrodes. Carbon Lett, 15, 162 (2014). http:// dx.doi.org/10.5714/CL.2014.15.3.162.

[9] DeValve C, Pitchumani R. Experimental investigation of the damping enhancement in fiber-reinforced composites with carbon nanotubes. Carbon, 63, 71 (2013). http://dx.doi.org/10.1016/j. carbon.2013.06.041.

[10] Jeong E, Kim J, Cho SH, Kim J, Han IS, Lee YS. New application of layered silicates for carbon fiber reinforced carbon composites. J Ind Eng Chem, 17, 191 (2011). http://dx.doi.org/10.1016/j. jiec.2011.02.032.

[11] Choi KE, Seo MK. A study on the preparation of the eco-friendly carbon fibers-reinforced composites. Carbon Lett, 14, 58 (2013) http://dx.doi.org/10.5714/CL.2012.14.1.058.

[12] Kim BH, Yang KS. Structure and electrochemical properties of electrospun carbon fiber composites containing grapheme J Ind Eng Chem, 20, 3474 (2014). http://dx.doi.org/10.1016/j. jiec.2013.12.037.

[13] Hu X, Wang L, Xu F, Xiao T, Zhang Z. In situ observations of fractures in short carbon fiber/epoxy composites. Carbon, 67, 368 (2014). http://dx.doi.org/10.1016/j.carbon.2013.10.007.

[14] Hong MS, Choi WK, An KH, Kang SJ, Park SJ, Lee YS, Kim BJ. Electromagnetic interference shielding behaviors of carbon fibersreinforced polypropylene matrix composites: II. Effects of filler length control. J Ind Eng Chem, 20, 3901 (2014). http://dx.doi. org/10.1016/j.jiec.2013.12.096.

[15] Zhang H, Zhang Z, Breidt C. Comparison of short carbon fibre surface treatments on epoxy composites: I. Enhancement of the mechanical properties. Compos Sci Technol, 64, 2021 (2004). http:// dx.doi.org/10.1016/j.compscitech.2004.02.009.

[16] Donnet JB, Park SJ. Surface characteristics of pitch-based carbonfibers by inverse gas-chromatography method. Carbon, 29, 955 (1991). http://dx.doi.org/10.1016/0008-6223(91)90174-H

[17] Hong J, Park DW, Shim SE. A review on thermal conductivity of polymer composites using carbon-based fillers: carbon nanotubes and carbon fibers. Carbon Lett, 11, 347 (2010).

[18] Zhang ZZ, Song HJ, Men XH, Luo ZZ. Effect of carbon fibers surface treatment on tribological performance of polyurethane (PU) composite coating. Wear, 264, 599 (2008). http://dx.doi 
org/10.1016/j.wear.2007.05.003.

[19] Qin RY, Donnet JB. Influence of thermal and surface treatments on surface properties of pitch-based carbon fibers studied by inverse gas chromatography. Carbon, 32, 165 (1994). http://dx.doi. org/10.1016/0008-6223(94)90022-1.

[20] Yang XP, Wang CZ, Yu YH, Ryu SK. Improvement of CF/ABS composite properties by anodic oxidation of pitch based C-type carbon fiber. Carbon Lett, 3, 80 (2002).

[21] Park SJ, Seo MK. Carbon fiber-reinforced polymer composites: preparation, properties, and applications. In: Thomas S, Kuruvilla J, Malhotra SK, Goda K, Sreekala MS, eds. Polymer Composites: Volume 1, Wiley-VCH Verlag GmbH \& Co. KGaA, 135 (2012). http://dx.doi.org/10.1002/9783527645213.ch5.

[22] Park SJ, Jang YS, Kawasaki J. Studies on nanoscaled Ni-P plating of carbon fiber surfaces in a composite system. Carbon Lett, 3, 77 (2002).

[23] Marieta C, Schulz E, Irusta L, Gabilondo N, Tercjak A, Mondragon I. Evaluation of fiber surface treatment and toughening of thermoset matrix on the interfacial behaviour of carbon fiber-reinforced cyanate matrix composites. Compos Sci Technol, 65, 2189 (2005). http://dx.doi.org/10.1016/j.compscitech.2005.05.008.

[24] Park SJ, Kim MH. Effect of acidic anode treatment on carbon fibers for increasing fiber-matrix adhesion and its relationship to interlaminar shear strength of composites. J Mater Sci, 35, 1901 (2000). http://dx.doi.org/10.1023/A:1004754100310.

[25] Park SJ, Cho KS, Ryu SK. Filler-elastomer interactions: influence of oxygen plasma treatment on surface and mechanical properties of carbon black/rubber. Carbon, 41, 1437 (2003). http://dx.doi. org/10.1016/S0008-6223(03)00088-5.

[26] He H, Wang J, Li K, Wang J, Gu J. Mixed resin and carbon fibres surface treatment for preparation of carbon fibres composites with good interfacial bonding strength. Mater Des, 31, 4631 (2010). http://dx.doi.org/10.1016/j.matdes.2010.05.031.

[27] Park SJ, Jang YS, Shim JW, Ryu SK. Studies on pore structures and surface functional groups of pitch-based activated carbon fibers. J Colloid Interface Sci, 260, 259 (2003). http://dx.doi.org/10.1016/ S0021-9797(02)00081-4.

[28] Park SJ, Seo MK, Lee YS. Surface characteristics of fluorinemodified PAN-based carbon fibers. Carbon, 41, 723 (2003). http:// dx.doi.org/10.1016/S0008-6223(02)00384-6.

[29] Park SJ, Park BJ. Electrochemically modified PAN carbon fibers and interfacial adhesion in epoxy-resin composites. J Mater Sci Lett, 18, 47 (1999). http://dx.doi.org/10.1023/A:1006673309571.

[30] Park SJ, Kim BJ. Effect of Ni plating on mechanical interfacial properties of carbon fibers-reinforced composites. Carbon Lett, 3, 152 (2002).

[31] Cao H, Huang Y, Zhang Z, Sun J. Uniform modification of carbon fibers surface in 3-D fabrics using intermittent electrochemical treatment. Compos Sci Technol, 65, 1655 (2005). http://dx.doi. org/10.1016/j.compscitech.2005.02.018.

[32] Park SJ, Seo MK, Lee YS. Surface and mechanical interfacial properties of oxyfluorinated carbon fibers-reinforced composites. Carbon Lett, 4, 69 (2003).

[33] Jin FL, Lee SY, Park SJ. Polymer matrices for carbon fiber-reinforced polymer composites. Carbon Lett, 14, 76 (2013). http:// dx.doi.org/10.5714/CL.2013.14.2.076.

[34] Park SJ, Jin FL, Lee JR. Synthesis and thermal properties of epoxidized vegetable oil. Macromol Rapid Commun, 25, 724 (2004). http://dx.doi.org/10.1002/marc.200300191.
[35] Vieille B, Casado VM, Bouvet C. About the impact behavior of woven-ply carbon fiber-reinforced thermoplastic- and thermosetting-composites: a comparative study. Compos Struct, 101, 9 (2013). http://dx.doi.org/10.1016/j.compstruct.2013.01.025.

[36] Park SJ, Jin FL, Lee JR. Thermal and mechanical properties of tetrafunctional epoxy resin toughened with epoxidized soybean oil. Mater Sci Eng A, 374, 109 (2004). http://dx.doi.org/10.1016/j. msea.2004.01.002.

[37] Jin FL, Park SJ. Recent advances in carbon-nanotube-based epoxy composites. Carbon Lett, 14, 1 (2013). http://dx.doi.org/10.5714/ CL.2012.14.1.001.

[38] Park SJ, Jin FL, Lee JR. Effect of biodegradable epoxidized castor oil on physicochemical and mechanical properties of epoxy resins. Macromol Chem Phys, 205, 2048 (2004). http://dx.doi. org/10.1002/macp.200400214.

[39] Park SJ, Oh JS, Rhee KY. Effect of atmospheric plasma treatment of carbon fibers on crack resistance of carbon fibers-reinforced epoxy composites. Carbon Lett, 6, 106 (2005).

[40] Park SJ, Jin FL. Thermal stabilities and dynamic mechanical properties of sulfone-containing epoxy resin cured with anhydride. Polym Degrad Stab, 86, 515 (2004). http://dx.doi.org/10.1016/j. polymdegradstab.2004.06.003.

[41] Huang Z, Sugiyama S, Yanagimoto J. Hybrid joining process for carbon fiber reinforced thermosetting plastic and metallic thin sheets by chemical bonding and plastic deformation. J Mater Process Technol, 213, 1864 (2013). http://dx.doi.org/10.1016/j.jmatprotec.2013.04.015.

[42] Park SJ, Jin FL, Lee C. Preparation and physical properties of hollow glass microspheres-reinforced epoxy matrix resins. Mater Sci Eng A, 402, 335 (2005). http://dx.doi.org/10.1016/j. msea.2005.05.015

[43] Park SJ, Jin FL, Nicolais L. Epoxy resins: fluorine systems. In Wiley Encyclopedia of Composites, John Wiley \& Sons, 842 (2011). http://dx.doi.org/10.1002/9781118097298.weoc076.

[44] Zhang G, Sun S, Yang D, Dodelet JP, Sacher E. The surface analytical characterization of carbon fibers functionalized by $\mathrm{H}_{2} \mathrm{SO}_{4} / \mathrm{HNO}_{3}$ treatment. Carbon, 46, 196 (2008). http://dx.doi. org/10.1016/j.carbon.2007.11.002.

[45] Li J, Cai CL. The carbon fiber surface treatment and addition of PA6 on tensile properties of ABS composites. Curr Appl Phys, 11, 50 (2011). http://dx.doi.org/10.1016/j.cap.2010.06.017.

[46] Seo MK, Park SJ. Surface characteristics of carbon fibers modified by direct oxyfluorination. J Colloid Interface Sci, 330, 237 (2009). http://dx.doi.org/10.1016/j.jcis.2008.10.005.

[47] Park SJ, Seo MK, Lee JR. Relationship between surface characteristics and interlaminar shear strength of oxyfluorinated carbon fibers in a composite system. J Colloid Interface Sci, 268, 127 (2003). http://dx.doi.org/10.1016/S0021-9797(03)00718-5.

[48] Lee JS, Kang TJ. Changes in physico-chemical and morphological properties of carbon fiber by surface treatment. Carbon, 35, 209 (1997). http://dx.doi.org/10.1016/S0008-6223(96)00138-8.

[49] Ryu SK, Park BJ, Park SJ. XPS analysis of carbon fiber surfaces-anodized and interfacial effects in fiber-epoxy composites. J Colloid Interface Sci, 215, 167 (1999). http://dx.doi.org/10.1006/ jcis.1999.6240.

[50] Osbeck S, Ward S, Idriss H. Effect of UV and electrochemical surface treatments on the adsorption and reaction of linear alcohols on non-porous carbon fibre. Appl Surf Sci, 270, 272 (2013). http:// dx.doi.org/10.1016/j.apsusc.2012.12.173. 
[51] Park SJ, Kim MH, Lee JR, Choi S. Effect of fiber-polymer interactions on fracture toughness behavior of carbon fiber-reinforced epoxy matrix composites. J Colloid Interface Sci, 228, 287 (2000). http://dx.doi.org/10.1006/jcis.2000.6953.

[52] Park SJ, Kim BJ. Roles of acidic functional groups of carbon fiber surfaces in enhancing interfacial adhesion behavior. Mater Sci Eng A, 408, 269 (2005). http://dx.doi.org/10.1016/j.msea.2005.08.129.

[53] Park SJ, Donnet JB. Anodic surface treatment on carbon fibers: determination of acid-base interaction parameter between two unidentical solid surfaces in a composite system. J Colloid Interface Sci, 206, 29 (1998). http://dx.doi.org/10.1006/jcis.1998.5672.

[54] Yuan LY, Chen CS, Shyu SS, Lai JY. Plasma surface treatment on carbon fibers. Part 1: Morphology and surface analysis of plasma etched fibers. Compos Sci Technol, 45, 1 (1992). http://dx.doi. org/10.1016/0266-3538(92)90116-K.

[55] Li H, Liang H, He F, Huang Y, Wan Y. Air dielectric barrier discharges plasma surface treatment of three-dimensional braided carbon fiber reinforced epoxy composites. Surf Coat Technol, 203, 1317 (2009). http://dx.doi.org/10.1016/j.surfcoat.2008.10.042.

[56] Iwashita N, Psomiadou E, Sawada Y. Effect of coupling treatment of carbon fiber surface on mechanical properties of carbon fiber reinforced carbon composites. Composites A, 29, 965 (1998). http:// dx.doi.org/10.1016/S1359-835X(97)00095-X.

[57] Zhang X, Huang Y, Wang T, Liu L. Influence of fibre surface oxidation-reduction followed by silsesquioxane coating treatment on interfacial mechanical properties of carbon fibre/polyarylacetylene composites. Composites A, 38, 936 (2007). http://dx.doi. org/10.1016/j.compositesa.2006.07.003.

[58] Park SJ, Jang YS. X-ray diffraction and X-ray photoelectron spectroscopy studies of Ni-P deposited onto carbon fiber surfaces impact properties of a carbon-fiber-reinforced matrix. J Colloid Interface Sci, 263, 170 (2003). http://dx.doi.org/10.1016/S00219797(03)00290-X

[59] Park SJ, Jang YS. Interfacial characteristics and fracture toughness of electrolytically Ni-plated carbon fiber-reinforced phenolic resin matrix composites. J Colloid Interface Sci, 237, 91 (2001). http:// dx.doi.org/10.1006/jcis.2001.7441.

[60] Barton JM, Hamerton I, Jones JR, Stedman JC. Mechanical properties of tough, high temperature carbon fibre composites from novel functionalized aryl cyanate ester polymers. Polymer, 37, 4519 (1996). http://dx.doi.org/10.1016/0032-3861(96)00053-5.

[61] Ren P, Liang G, Zhang Z. Epoxy-modified cyanate ester resin and its high- modulus carbon-fiber composites. Polym Compos, 27, 402 (2006). http://dx.doi.org/10.1002/pc.20207.

[62] Ren P, Liang G, Zhang Z. Influence of epoxy sizing of carbon-fiber on the properties of carbon fiber/cyanate ester composites. Polym Compos, 27, 591 (2006). http://dx.doi.org/10.1002/pc.20230.

[63] Dong W, Liu HC, Park SJ, Jin FL. Fracture toughness improvement of epoxy resins with short carbon fibers. J Ind Eng Chem, 20, 1220 (2014). http://dx.doi.org/10.1016/j.jiec.2013.06.053.

[64] Park SJ, Jang YS, Rhee KY. Interlaminar and ductile characteristics of carbon fibers-reinforced plastics produced by nanoscaled electroless nickel plating on carbon fiber surfaces. J Colloid Interface Sci, 245, 383 (2002). http://dx.doi.org/10.1006/jcis.2001.8040

[65] Park SJ, Seo MK, Rhee KY. Studies on mechanical interfacial properties of oxy-fluorinated carbon fibers-reinforced composites. Mater Sci Eng A, 356, 219 (2003). http://dx.doi.org/10.1016/ S0921-5093(03)00134-5.

[66] Moaseri E, Maghrebi M, Baniadam M. Improvements in mechani- cal properties of carbon fiber-reinforced epoxy composites: a microwave-assisted approach in functionalization of carbon fiber via diamines. Mater Des, 55, 644 (2014). http://dx.doi.org/10.1016/j. matdes.2013.10.040

[67] Siegfried M, Tola C, Claes M, Lomov SV, Verpoest I, Gorbatikh L. Impact and residual after impact properties of carbon fiber/epoxy composites modified with carbon nanotubes. Compos Struct, 111 488 (2014). http://dx.doi.org/10.1016/j.compstruct.2014.01.035.

[68] Choi MH, Jeon BH, Chung IJ. The effect of coupling agent on electrical and mechanical properties of carbon fiber/phenolic resin composites. Polymer, 41, 3243 (2000). http://dx.doi.org/10.1016/ S0032-3861(99)00532-7.

[69] Vilc $\square$ áková J, Sáha $\mathrm{P}, \mathrm{Kr} \square$ esálek V, Quadrat O. Pre-exponential factor and activation energy of electrical conductivity in polyester resin/carbon fibre composites. Synth Met, 113, 83 (2000). http:// dx.doi.org/10.1016/S0379-6779(99)00454-3

[70] Vilčáková J, Sáha P, Quadrat O. Electrical conductivity of carbon fibres/polyester resin composites in the percolation threshold region. Eur Polym J, 38, 2343 (2002). http://dx.doi.org/10.1016/ S0014-3057(02)00145-3.

[71] Yudin VE, Goykhman MY, Balik K, Glogar P, Gubanova GN, Kudriavtsev VV. Carbonization behaviour of some polyimide resins reinforced with carbon fibers. Carbon, 38, 5 (2000). http://dx.doi. org/10.1016/S0008-6223(99)00073-1.

[72] Mascia L, Zhang Z, Shaw SJ. Carbon fibre composites based on polyimide/silica ceramers: aspects of structure-properties relationship. Composites A, 27, 1211 (1996). http://dx.doi org/10.1016/1359-835X(96)00082-6.

[73] Liu A, Guo M, Gao J, Zhao M. Influence of bond coat on shear adhesion strength of erosion and thermal resistant coating for carbon fiber reinforced thermosetting polyimide. Compos Sci Technol, 201, 2696 (2006). http://dx.doi.org/10.1016/j.surfcoat.2006.05.012.

[74] Xu J, Donohoe JP, Pittman CU Jr. Preparation, electrical and mechanical properties of vapor grown carbon fiber (VGCF)/vinyl ester composites. Composites A, 35, 693 (2004). http://dx.doi. org/10.1016/j.compositesa.2004.02.016.

[75] Kumar S, Satapathy BK, Patnaik A. Thermo-mechanical correlations to erosion performance of short carbon fibre reinforced vinyl ester resin composites. Mater Des, 32, 2260 (2011). http://dx.doi. org/10.1016/j.matdes.2010.11.019.

[76] Kumar S, Satapathy BK, Patnaik A. Thermo-mechanical correlations to erosion performance of short glass/carbon fiber reinforced vinyl ester resin hybrid composites. Comput Mater Sci, 60, 250 (2012). http://dx.doi.org/10.1016/j.commatsci.2012.03.021.

[77] Chung K, Seferis JC. Evaluation of thermal degradation on carbon fiber/cyanate ester composites. Polym Degrad Stab, 71, 425 (2001). http://dx.doi.org/10.1016/S0141-3910(00)00194-4.

[78] Li J, Fan Q, Chen Z, Huang K, Cheng Y. Effect of electropolymer sizing of carbon fiber on mechanical properties of phenolic resin composites. Trans Nonferrous Met Soc China, 16, S457 (2006). http://dx.doi.org/10.1016/S1003-6326(06)60233-1.

[79] Marković V, Marinković S. A study of pyrolysis of phenolic resin reinforced with carbon fibers and oxidized PAN fibres. Carbon, 18 329 (1980). http://dx.doi.org/10.1016/0008-6223(80)90004-4.

[80] Singh AP, Garg P, Alam F, Singh K, Mathur RB, Tandon RP, Chandra A, Dhawan SK. Phenolic resin-based composite sheets filled with mixtures of reduced graphene oxide, $\gamma-\mathrm{Fe}_{2} \mathrm{O}_{3}$ and carbon fibers for excellent electromagnetic interference shielding in the X-band. Carbon, 50, 3868 (2012). http://dx.doi.org/10.1016/j.car- 
bon.2012.04.030.

[81] Wyatt RC, Ashbee KHG. Debonding in carbon fiber/polyester resin composites exposed to water: comparison with 'E' glass fiber composites. Fibre Sci Tech, 2, 29 (1969). http://dx.doi. org/10.1016/0015-0568(69)90029-3.

[82] Sadeghian R, Gangireddy S, Minaie B, Hsiao KT. Manufacturing carbon nanofibers toughened polyester/glass fiber composites using vacuum assisted resin transfer molding for enhancing the mode-I delamination resistance. Composites A, 37, 1787 (2006). http://dx.doi.org/10.1016/j.compositesa.2005.09.010.

[83] Hsiao KT, Gangireddy S. Investigation on the spring-in phenomenon of carbon nanofiber-glass fiber/polyester composites manufactured with vacuum assisted resin transfer molding. Composites A, 39, 834 (2008). http://dx.doi.org/10.1016/j.compositesa.2008.01.015.

[84] Srivastava VK, Rastogi A, Goel SC, Chukowry SK. Implantation of tricalcium phosphate-polyvinyl alcohol filled carbon fibre reinforced polyester resin composites into bone marrow of rabbits. Mater Sci Eng A, 448, 335 (2007). http://dx.doi.org/10.1016/j. msea.2006.11.004

[85] Xie J, Xin D, Cao H, Wang C, Zhao Y, Yao L, Ji F, Qiu Y. Improving carbon fiber adhesion to polyimide with atmospheric pressure plasma treatment. Surf Coat Technol, 206, 191 (2011). http:// dx.doi.org/10.1016/j.surfcoat.2011.04.016.

[86] Naganuma T, Naito K, Yang JM, Kyono J, Sasakura D, Kagawa $\mathrm{Y}$. The effect of a compliant polyimide nanocoating on the tensile properties of a high strength PAN-based carbon fiber. Compos Sci Technol, 69, 1319 (2009). http://dx.doi.org/10.1016/j.compscitech.2009.03.002.

[87] Verghese KNE, Jensen RE, Lesko JJ, Ward TC. Effects of molecular relaxation behavior on sized carbon fiber-vinyl ester matrix composite properties. Polymer, 42, 1633 (2001). http://dx.doi org/10.1016/S0032-3861(00)00351-7.

[88] Wonderly C, Grenestedt J, Fernlund G, Cěpus E. Comparison of mechanical properties of glass fiber/vinyl ester and carbon fiber/vinyl ester composites. Composites B, 36, 417 (2005). http://dx.doi. org/10.1016/j.compositesb.2005.01.004. 